\title{
Illuminating Cultural Terrains in Dance: A Symbiotic Approach to Analysis and Interpretation
}

\section{Introduction}

In a paper that I presented at Atarau Academic Symposium, and later developed in an article for Dance Research Aotearoa (Ashley, 2015), I argued that the colloquial understanding of dance as one universal language provides insufficient philosophical grounds for fostering a full understanding of contemporary, indigenous, intercultural dance. Nourishing an awareness of how dance can be understood not as one but many languages is important because it can, I contend, inform ethical practices in dance, and foster better understanding and appreciation of dance practices from diverse cultures. In the article for Dance Research Aotearoa I stated that:

Translating dances as semiotically, languageladen signs is quite a different approach to the application of Western Laban analysis and as such can reveal more about the intercultural terrains of indigenous contemporary dance.

Moreover, it could go some way towards establishing what marks indigenous contemporary dance' as different from other contemporary dance; a question that was discussed by delegates of Atarau. (2015) 
Drawing on the semiotics of C. S. Peirce and his observations about human language, I now embark on a new trajectory by applying it to interpret an indigenous contemporary dance in symbiosis with what many contemporary dance practitioners, educators and academics apply as they study, teach and make dance, Laban movement analysis. Via a process of applying a Laban ${ }^{1}$ movement analysis alongside a Peircean semiotic interpretation I endeavour not only to illuminate some significances of a Māori contemporary dance made in New Zealand but also to illustrate how useful Peirce's semiotic theory is for revealing what is socio-culturally significant in dance. Together these two methods, I argue, could add up to greater understanding of culturally diverse dances.

Also, I aim to provide further reasons why I advocate for the practice of semiotically translating dance. I identify some important benefits of applying such philosophical underpinnings to practices in which we endeavour to better understand dance, advocate for its importance as an art form and promote it as beneficial for many in the arts and educational arenas, and for society at large.

Following this introduction I provide some personal background pertaining to my experience and involvement in dance and specifically related to the use of Laban's work. Drawing on dance and anthropological research, I then explain why and how a process that combines Laban movement analysis with a Peircean semiotic translation could further inform current dance studies. In a section that presents Peirce's theory about human language I make suggestions about how such a philosophical underpinning can benefit stakeholders in dance, and I also explain how a semiotic strategy can illuminate culturally diverse dance languages. Relatively brief explanations of Peirce's classification and

1 I draw on Laban terminologies as found in Preston, V. (1963) A handbook for modern educational dance. London: MacDonald \& Evans. Preston was a pupil of Laban and this book was a basic text in my undergraduate studies. 
functionality of signs and of the value of the symbiotic process follow. Then, in order to demonstrate how these aspects of semiotics are useful for those who make and view dances, I apply them, in symbiosis with Laban movement analysis, to illuminate the layered cultural significances of a Māori contemporary dance.

\section{Background}

Having spent 40 years in dance practice and theory I have been a prolific user and advocate for the work of Rudolf Laban. I was trained in Laban work. In both the UK and New Zealand, my use of Laban approaches has developed from: undergraduate studies at I. M. Marsh College, University of Liverpool; Masters studies at the Laban Centre, Goldsmith's College and The University of London; and doctoral study at The University of Auckland, New Zealand. I have used Laban's strategies and movement terminologies in choreography, performance, as an educator and since 1996 in my writing (Ashley 2008, 2012, 2013, 2014). I also have a background in contemporary dance technique, choreography and performance. Together these tools have provided me with a language that can be understood internationally and a career with international profile.

Originating from the early $20^{\text {th }}$ century practice and theory of Rudolf Laban, a set of terminologies are used in the worldwide dance industry. Laban's terms and creative practices are ubiquitous in texts, school curricula and dance making internationally. In more recent times his work has been given a certain sense of lesser importance because he has been seen as misogynist and a Nazi supporter (Kant, 2008). Indeed, seen through a $21^{\text {st }}$ century lens these accusations could be valid. Nevertheless, the body of work and cultural legacy is still in use globally, sadly sometimes without understanding or recognition of its origins (Lepczyk, 2009).

Laban was the first to analyse movement into 16 Basic 
Movement Themes (the Dance Elements as they are often referred to) of body, time, weight, space and relationships. More broadly and poignant is the fact that the 'creative dance' process pervasive in current professional choreographic collaborative practices, community dance and educational settings worldwide could be said to emerge, in part at least, from Laban's core approach. Models for dance education in Europe and the USA draw on Laban's movement analysis, recognising that "as a basic tool for dance composition [it] is unsurpassed in that it dissects the total range of human movement into easily recognisable and descriptive frames of reference" (Smith-Autard, 2002, p. 7).

Laban associated 'neutral' movement categories of the Dance Elements, with Western social values and meanings of his day, such as found in pairing specific weight, space and time qualities for characters of demon, goddess, politician and Samaritan (Laban, 1960). Nevertheless, Laban's movement analysis can be seen as having potential to increase the possibility of understanding how human movement can carry many different cultural meanings through dancing. Movement analysis is, however, only part of the solution in illuminating cultural terrains in dances.

\section{Why a combined analytic and semiotic interpretive approach?}

So if Laban's dance analysis is useful in understanding dances of other cultures why might a supplementary approach be required? In engaging with a combination of an analytic and semiotic interpretive processes, I entertain a challenge that was outlined recently by a colleague (who wishes to remain anonymous). In referring to how she needed to re-read Peirce's work in order to understand the relevance of Peirce's theory for dance I realised that I needed to provide a clear and useful explanation of how it can benefit and be applied to dance.

Readers may identify with this line of thought. Indeed 
to read Peirce's original works is something that could consume more time and life force than most dance academics can afford. It is also unlikely that, given Peirce's usage of a language style from the end of the $19^{\text {th }}$ century, there are many who would read it for enjoyment. I read it because it was pertinent to my doctorate studies. There are, however, arts educators who work with semiotics and Peirce in particular (Semetsky \& Stables, 2014). This article is written mindful of the work of other academic and dance research colleagues, however, I am not presenting a literature review. Rather, in considering my colleague's perspective, I set out to clarify how reading dance from within a semiotically based language framework could further inform current dance study, and possibly produce a rationale from which intercultural, indigenous contemporary dance and single culture indigenous dance may be better understood, strengthened and supported.

The cross-cultural use of Laban's analytical Movement Themes remains valid but interpretation is a separate issue. As Jane Desmond (1997) pointed out, in order to analyse how identities are 'codified' and how socio-cultural norms are contested, amplified or exceeded within specific contexts in dance, comparative study of "symbolic systems based on language, visual representation and movement" (p. 29) could be productive in studying complex kinaesthetic semiotics. Intent on studying movements as texts and confirming the appropriateness of Laban analysis Desmond noted that:

To keep our broader levels of analysis anchored in the materiality and kinesthesia of the dancing body, we need to generate more tools for the close readings, and more sophisticated methodologies for shuttling back and forth between the micro (physical) and the macro (historical, ideological) levels of movement investigation. (p. 50) 
Enter Peircean semiotic analysis. Henrietta Bannerman (2010) expresses surprise that Peircean semiotics has not been used to study dance more, as it has in theatre studies. She applied Peirce's semiotics to interpret Western modern / contemporary dance "in order to demonstrate how we can deepen our understanding of the communicative properties of dance" ( $p$. 19). Also, she correctly notes that Peirce, “...spearheaded many of the theories which still engage us” (p. 20).

Strategies used by some anthropologists of dance reveal a helpful illustration of how the concept of dance languages and semiotic interpretation can be useful in fostering understanding of dance (Kaeppler, 2005; Williams, 2003). Brenda Farnell (2003) acknowledges Peirce's influence alongside Saussure and Wittgenstein as influential in contemporary linguistic anthropology. Also, Farnell (1999) identifies 'simultaneity' of kinaesthetic and vocal utterances, reinforcing how movement, linguistic signs and deictic (local) ${ }^{2}$ significance can be inextricably linked in human thought and action. She (1994) uses Labanotation to notate a hand gesture from the North American Plains People, Assinibone Plains Sign Talk, revealing how Assinibone concepts of north, south, east and west as tracks of the four winds coming towards a person, contrast with European ones of these as linear directions that stretch away from the person. In revealing multimodal semiotic talk 'from' the body (1994, p. 941), Farnell identifies relevant deictic significance within a pluralistic, dialogic and sentient view of making meanings in movement.

Making use of Peircean semiotics and Laban movement analysis as a symbiotic system for translating dances when illuminating performances of cultural identities

2 Derived from the Greek, meaning pointing or indicating, 'deixis' is relative to space and time. It includes personal pronouns and adverbials of time and space, as well as demonstratives in the present tense (Farnell, 1994). Hence, the full semantic meanings of words as signs, such as, 'this', 'there', 'here', 'now' and 'then' are found only in reference to the linguistic cultural context in which they are used. 
and ideologies is the focus of this article. In order to further explain why and how semiotic translation can effectively illuminate dance I now provide a brief overview of Peirce's views on language.

\section{Peirce on Language: Valuing and understanding dance semiotically}

One aspect of conceptualising the 'languages of dance' that I feel that I have not emphasised as much as I could do are the implications of the semiotics of Charles S. Peirce (1839 1914). In referring to Peirce's emphasis on language as central to making and interpreting meaning in the human condition, I first emphasise a benefit for dance that his semiotic depiction of language affords:

[M]eaning the mode of expression between man and man, by Meaning - whether this Language consists of gestures or speech or music or what. (Peirce, 1982, p. 86)

Peirce's statement awards dances, as languages of gestures, equitable status alongside spoken languages, and other types of languages. Therefore, I argue that one benefit of a Peircean semiotic, language rich translation of dance for dance practitioners, researchers and educators is in establishing a rationale that provides dance with equal status alongside other forms of human knowledge.

This perspective has some commonality with the notion of multi literacies as derived from The New London Group (1996). The recognition of multiple literacies across fields of knowledge, such as science and media, emancipates the arts as one of many social discourses in education and society. All of the arts are recognised as having political, social and cultural significances, the meaning of which is context dependent, and "[s]uch literacy is grounded in the study of the 
language and grammar of each art form" (New Zealand Ministry of Education, 1999, p. 17). From this perspective a previous notion of literacy as the 3 R's is replaced by one in which a multiplicity of socially constructed discourses is recognised. I agree that this is the case but an added strength brought by the semiotic study of dance specifically is found in the way that dance can be best understood as existing alongside, in parallel or overlapping with spoken and written language-signs rather than separate from them.

In dance making, running parallel to the aesthetic choices from the Dance Elements, choreographers may select themes and metaphors from the everyday (metonymic), and in so doing dances can be language like and/or relate to verbal language indirectly and directly. Dances and the meanings that they carry, as the late arts philosopher David Best explained, "can be regarded as an analogy of the response to a situation in life" (1985, p. 180). Consequently, if a viewer can grasp the analogies carried by a dance s/he could better understand its cultural worldview.

Such a perspective is captured in the statement: "Dance uses movement as poetic language" (Laban, 1960, p. 91). Roman Jakobson's ${ }^{3}$ (1997) double functionalist semiotic view of language, offers apposite additional semiotic theory relevant to dance. Jakobson identified poetry as having a double functionality via its inclusion of metaphors or everyday meanings (metonymy) and semantic, rhythmical and sound qualities. Interpretation of the verbal richness of poetry distinguishes it from ordinary speech by relating to the reader's knowledge of wider literary codes. Therefore, drawing similarities of artistic form and social function between poetry and dance, I propose, can indicate how understanding dances as language-laden signs requires familiarity with dance literacies and worldviews as defined and shaped by people

3 Jakobson was a linguist and co-founder, with Claude Lévi-Strauss of modern structuralism in the 1920s. See also Jordan \& Thomas (1994). 
within the culture/s of origin. Peircean semiotics and Jakobson's double functionality provide substantial clarification and explanation with regard to how dance can be meaningfully interpreted within a semiotic, language-like frame. I argue that each dance language is infused with the associated spoken language/s, conceptual understandings and ideologies emanating from the culture of origin.

Translating the cultural shaping of identity and ideology becomes a necessary step in semiotically interpreting dance. The starting point for watching and interpreting is driven by an assumption that there are many dance languages that can be read as semiotic texts. ${ }^{4}$ Dance is not one but many languages and Peirce's theory of how humans make and interpret languages as signs is inherently dynamic ${ }^{5}$, making it appropriate for and empathic with illuminating dance, that most dynamic of art forms. I further suggest that by applying a process that symbiotically analyses and semiotically translates the dances of indigenous or First Nation cultures, and / or indigenous contemporary dance, understanding the ideologies of diverse cultural terrains that drive performances can be enhanced. As such, illuminating understandings of and respect for culturally diverse dance terrains via semiotic

4 I acknowledge that reading dance as texts is not new but I argue for a practical approach that utilises Peircean semiotics specifically, noting also that previous semiotic study of dance has drawn on various semiotic theories. One example is found in Janet Adshead-Lansdale (1999). Basing her study within Roland Barthes' demise of the author and readers' liberation front, she describes the way in which the reader mediates meaning and becomes "a co-creator of a mobile text, breathing new life into a dancing text" (p. 21). It is worth noting that such a meaning making process can be traced back to Peircean semeiosis, that is how humans think with signs.

5 Space does not afford further extrapolation on Peirce's semeiotic theory introduced in the 1860 s as a science of signs. Peirce's semeiosis portrays a 'lived', embodied reasoning process, active when humans interact with the world to make sense of everyday life. How we think with signs in dance is a topic that I hope to write about on a future occasion. 
translation could benefit contemporary indigenous choreographers and their communities by providing rationales for increased support.

\section{Peirce on signs}

Meeting Desmond's call for sophisticated methodologies, as a philosophical underpinning method Peircean semiotics could be demanding. Nevertheless, I feel, it is worth pursuing, and in this article I hope to provide a workable and accessible outline of its application and its usefulness for dance study and advocacy. Like many complex theories the complexity belies its simplicity. Simplicity is not always, however, easy to comprehend.

In 1897, Peirce defined a sign as being, "something which stands to somebody for something" (cited in Smith, 2005, p. 192). Peirce's three-fold classification of signs as icons, symbols and indexicals, is a complex theoretical area. ${ }^{6}$ However, the basis of the Peircean classification resides in a dynamic system of signs as mimetic, symbolic and deictic (meaningful in reference to the cultural context in which they are used).

In Peirce's (1960) classification of signs, icons visually resemble the object that they represent e.g. mimetic actions of paddling a canoe. Symbols have formal, conventional, arbitrary connections to cultural concepts e.g. as part of a complex sign system of hastas in Indian Bharatha Natyam, raising the thumb is called shikara and represents a spire or peak. This does not look like a peak, but a cultural collective agreement recognises it as arbitrarily and culturally connoting such. Indexicals are classed as signs that are physically contiguous with the object and include indications of human intention such as gestures, tone of voice and demonstrative

6 See Singer (1980) concerning the 66 kinds of signs delineated by Peirce. 
and personal pronouns for example, 'this', 'that' 'I' and 'you' (pp. 337 - 338). Peirce's examples of a weather vane reacting to the wind and the pointing finger are, to him, one and the same indexical signs. At first, this conflation may seem rather simplistic, the grouping of an intentional human act with a non-sentient object; a curious juxtaposition in such a complex theory. However, in the Peircean universe they both physically denote not only the meanings on their own surfaces, but also those of the surrounding contexts in which communication occurs. The outcome is the study of "indexicality, how one thing signals the spatial, temporal, or causal co-presence of another" (Silverstein, 2000, p. 78).

Indexicality becomes a more profoundly meaningful concept once the following is considered, "the word or sign which man uses is the man himself... man is a sign" (Peirce, 1982a, p. 241). Peirce's positioning of thoughts as active and embodied, reveals that each one of us is a sign (if a complex one) acting out our part in the world. I argue that an indexical, embodied philosophical platform for human thought offers dimensions of local significance (deictic) and identity giving Peirce's semiotics a special relevance as a strategy for studying dance in a more worldly manner than Laban analysis. It also meets Desmond's (1997) criteria for a methodology that can shuttle back and forth between the physical and the contextual significations.

Dances as indicators of cultural ideologies, identities and concepts are the nut of the indexical issue for illuminating the indigenous in contemporary dance. However, in expressive cultural practices signs operate in dynamic interaction. The translucence of dance meaning is such that dances can be sites where all three of Peirce's signs interdependently oscillate as they are experienced by dancers and viewers. This is where Peirce's semiotics can become so vibrant in illuminating cultural terrains in dances. 


\section{Peircean semiotic translation and Laban analysis: Working in symbiosis to illuminate indigenous contemporary dance} In my previous article (2015) I explored and explained how indigenous contemporary dance can create a surplus of meaning that can be demanding for the viewer to understand. Certainly as Sharon Mazer (2013) points out, in Barthesian mood, different viewers can create their own meanings that in their own right are valid and valuable in opening up new discourse. A certain ambiguity of meaning has often been associated with Western contemporary dance as a kind of badge of identity for the form. An ambiguity challenged by Henrietta Bannerman (2010) in relation to dance by renowned postmodern choreographer Merce Cunningham:

The application of a Peircean semiotic model to Cunningham's work reveals that his movement vocabulary for Points in Space is not, as Foster suggests, arbitrary or non-referential. Rather, his choreography embodies iconic indexes of a societal world of human behaviour and endeavour, as well as of life as it is lived by animals, topics which have interested Cunningham throughout his career. (p. 31)

In view of this sidestep away from a totalitarian Barthesian ambiguity and genocide of authors, I am ever curious about if viewers, as they manoeuvre their way through what Terry Eagleton described as "a constrained affair" (1996, p. 75), may wish to discover what the artist's worldview entails. There is also some desire possibly on the part of the artist to be heard, particularly when addressing:

Concepts of cultural resistance, appropriation, and cultural imperialism important for the light they shed on unequal distribution of power and 
goods that shape social relations. (Desmond, 1997, p. 49)

Assuming that dance can codify identities, and contest, amplify or confront socio-cultural norms, then providing a suitable tool by which to foster understanding is, I argue, important in respecting and possibly valuing the artist's worldview. Indeed, as Sharon Mazer (2011) and Peter Cleave (2014) have observed Māori kapa haka can sometimes be seen as a theatre of resistance. Hence a haka choreographers' worldviews can be laid down as a challenge, literally and metaphorically, for audiences to comprehend and consider. However, it could be helpful to know hat is being resisted and why. As such Peirce's icons, symbols and indexicals come into action with a language-laden ferocity. Applying what I suggest is a symbiotic use of Laban's movement analysis with a semiotic translation process could therefore be valuable not only for the artists but also for their heritages of origin and their people on socio-political terrains.

\section{Putting Peirce into symbiotic practice with Laban}

In order to take Peirce's semiotics out of the theoretical clouds and imbue it with some down-to-earth value for dance scholars, practitioners, educators, audiences and other stakeholders, I now apply it in symbiosis with Laban movement analysis to a striking and what I regard as cutting edge Māori indigenous contemporary dance. Rongo $(2014)^{7}$ by directors of Hawaiki TU, Kura Te Ua and Beez Ngarino Watt, is a work they describe as "Māori movement". Te Ua and Ngarino Watt are working in 'Haka Theatre'; a term that they explain was used over 100 years ago by Māori Princess Te Puea Herangi:

7 Performed by Kura Te Ua, Karena Koria, Sophie Williams and Beez Ngarino Watt. http://youtu.be/r7jV_S98Igg 
Haka Theatre is a term more aligned with the Māori ethic of creative process that combines elements of Kapa Haka, Māori Movement and Theatre. Māori Movement is one part of Haka Theatre. (Te Ua, K., personal communication, February 4, 2015)

Rongo was originally one section of a full-length work $T e$ Manawa (The Heart, 2014) made by Hawaiki TU as a celebration of Matariki (Māori New Year'). Hawaiki TU describe Te Manawa as infused with myth, language, music and dramatic dialogue. Matariki is traditionally for Māori a time for reflection on new beginnings that honour the past but look to the future. Te Manawa depicted themes of traditional horticulture, navigation and celebrating life that are traditionally associated with Matariki. Te Ua and Ngarino Watt later developed Rongo as a standalone trio". Rongo is "inspired by Rongo' te atua Māori (Māori God of agriculture and peace) and traditional forms of planting and cultivating - 'You reap what you sow'..."10

You reap what you sow reflects on our relationship to Papatuanuku the Earth mother and her calls/warnings to look after the earth, also the importance of staying connected to our land and the ways of our tupuna (tikanga, matauranga - knowledge, te reo māori, whanau, values) so that not only our future generations

8 Celebrated in May, Matariki is the name given to the cluster of stars (the constellation of Pleiades) that rises above the horizon and becomes visible in the pre-dawn sky in New Zealand.

9 The original version was for multiple dancers.

10 Te Ua \& Ngarino Watt, Programme note October 8 \& 9, Fresh presented by 2014 Tempo Dance Festival at Q Theatre, Auckland, New Zealand. 
have a strong foundation to build on but that we as the 'living forbearers' can succeed and move forward confidently in this fast evolving world. (Te Ua, K., personal communication, February 4, 2015)

In Te Ua's explanation, a metaphor of environmental concerns can be recognised as part of Rongo. Reading and translating the iconic, symbolic and indexically nuanced meanings, however, may not be easy for uninformed or illiterate viewers.

For this article I am going to limit my reading of Rongo to three characteristic features of the movement: dynamic range; arm and hand gestures; and group relationships. This provides a partial reading as appropriate for the word count of such papers as this and overlooks some body actions such as those of feet and legs, changes of level, posture and facial gestures. ${ }^{11}$

However, I would first like to acknowledge the live accompaniment provided by Beez Ngarino Watt because of its importance to the performance, feelings and impact of Rongo:

Actually its an impromptu karakia [a chant to the $\operatorname{gods}^{12}$ ] in the form of a chant, the beats and rhythms often remained the same, but sometimes (depending on how we were going) he would put a few other words of encouragement in to help lift the energy or sync us up if we were out. Ultimately it is a karakia to Rongo that we may embody his spirit within the work. (Te Ua, K., personal communication, February 4, 2015)

In this paper I am not providing a detailed description of the

11 I did some interpretation of these in Tanemahuta Gray's Pou (2012), see Ashley, 2015.

12 Buck, P. (1950) The coming of the Maori. Wellington: Whitcombe \& Tombs. 
karakia but am mindful of its importance to the synthesis of the performance and as a driver of the striking feature of a forceful performance quality. Nathan Matthews (2004) singles out that "it is the actual quality of the physical performance of haka that determines the effectiveness of message transmission" (p. 13). Judging the quality, Matthews explains, is via two criteria. First, the composition "the depth of language" and second the performer's use of the body. With regard to the latter, the performers in Rongo encapsulate a dominantly, although not entirely, explosive dynamic range that could be thought of as characteristic of many haka performances. It can be described in Laban terms as firm in the sense of weight of the movements, percussive in quality, sudden, direct in its use of space. It is seen in the forceful punches, slaps to the ground, fast slicing of the arms, piercing elbows, quick turns of the head, sudden pulling down and pushing up movements, and abrupt emphatic stillnesses that add rhythmic emphasis at the end of some phrases. The performers' voices also add plosive completions and releases of the phrasing in a poetically alliterative manner.

At this point it seems that Laban analysis falls short of what is needed in order to reach a fuller comprehension, so I turn to a Peircean semiotic reading of the explosive dynamic in order to illuminate the cultural signposts seen in Rongo. Based on an explanation that: "On the whole, the actions used in haka are strong and fierce regardless of their often friendly intent; they are expected to inspire awe and to impress the audience" (Matthews, 2004, p. 14), the explosive dynamic seems to act as a poetic indexical of its tikanga Māori (values and beliefs). The dominant dynamic indexically signals the spatial, temporal, or causal co-presence of Māori haka. As an indexical it scaffolds and supports the message of Rongo aesthetically and physically denoting the cultural context of Māori origin. 


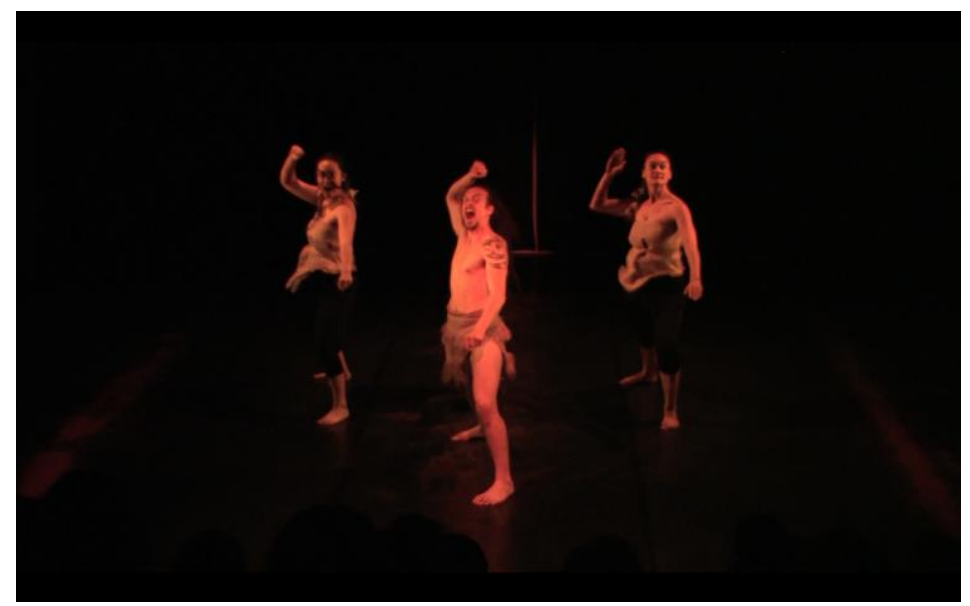

Rongo: Dancers (left to right) Sophie Williams, Karena Koria and Kura Te Ua

The dynamic could also be associated with Mazer's (2011) and Cleave's (2014) analysis of a theatre of resistance in which the on-stage revival of past beliefs intersects with the audience who watch in the present. This analysis permeates my interpretation and understanding, because in Rongo I connect with the performers' heartfelt raising of the wairua (the world that describes spirit) of Rongo' te atua. Implied is an allegoric sense that if you sow seeds of energy, integrity and honour the past that is what you will reap in the future. This interpretation of the dominant dynamic in Rongo could be understood as also functioning as a Peircean indexical sign because understanding it involves peeling back layers of Māori cultural beliefs, language and movement systems, in endeavours to unearth the seemingly arbitrary connections between the haka dynamic range and the meaning. The ubiquitous dynamic seems, to me at least, to connect with this succinct description of the function of haka:

It is disciplined, yet emotional. More than any other aspect of the Maori culture, this complex 
dance is an expression of the passion, vigour and identity of the race. It is, at its best, truly a message of the soul expressed by words and posture. (Armstrong, 1964, p. 119)

I connect with Armstrong here in recognising haka as complex and passionate, and in my semiotic translation of Rongo I hope to convey not only its complexity but how reaching in to that labyrinth of meaning can be a meandering yet constrained affair. Therefore, using Laban analysis alongside Peircean semiotic translation is producing an interesting result in drawing attention how a dynamic range, as a dominant feature in a dance, can indicate a culturally indigenous identity.

By way of contrast to the dominant explosive dynamic there are also tinges of a more sustained range. The closing section of Rongo is noticeably slower and less impulsive than previous sections, and it brings a sense of closure along with a hint that time continues from the past and on into the future. Perhaps revealing the limitations of Laban analysis, Rongo's dance vocabulary seems to break through the Laban tendency to divide movement as either firm and strong, or fine and delicate insofar as the movement sometimes hits the eye with both in an instant.

Mercurial dynamic changes flow through the body in one moment freely then in an instant captured and bound again in most surprising and skillful ways. Slower arm gestures (ringa) are initiated from sudden impulsive movements such as changes of facing, turns of heads. Sometimes these slower ringa are also performed with fiery energy. They are recognisably mimetic, iconic gestures of cultivation, planting seeds, pulling weeds, digging, and harvesting. 


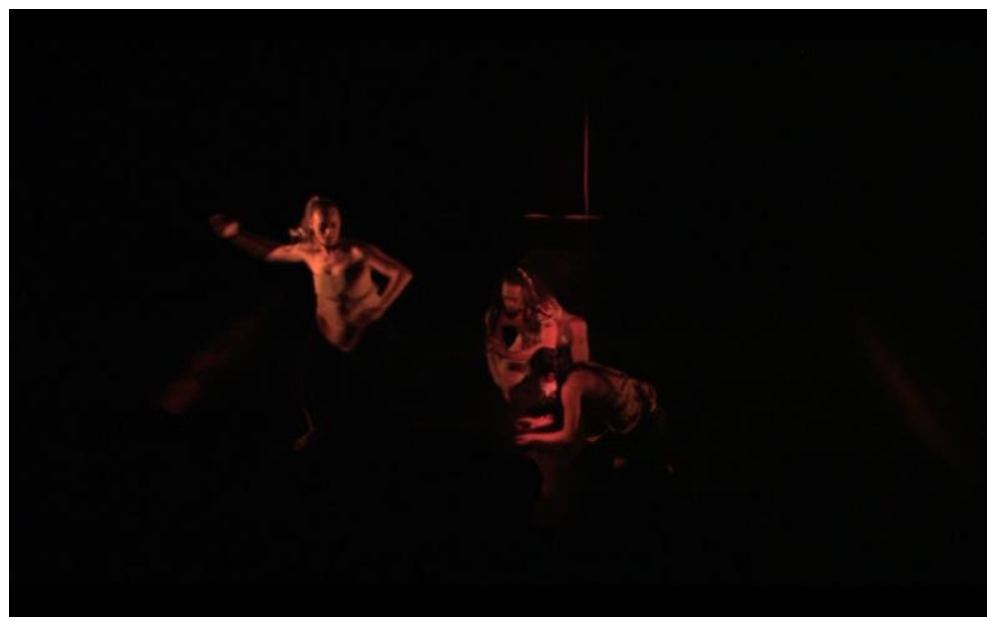

A repeated arm motif of raising the arms in a $\mathrm{V}$ shape up to the sky, sometimes gradually and other times more suddenly, likely as not denotes an appeal for recognition from Rongo' te atua for a blessing on the harvest / future. So in Rongo the mimetic, iconic arm gestures carry a double meaning. The first being mimetic but the second issuing a spirited challenge to the viewer, imploring them to reforge connections to the environment and each other, and in particular ones that relate to indigenous Māori beliefs, appropriate to the celebration of Matariki. This set of characteristics is key to understanding that although this could be described as a contemporary indigenous dance it is still very much a haka in its many of its choreographic conventions. ${ }^{13}$

13 Longstanding Māori contemporary dance artist Stephen Bradshaw notes that "Maori dance embodies the environment and our world has changed so much we should move with it". Readers may wish to read more from Māori contemporary dance practitioner Stephen Bradshaw

http://contemporarymaoridance.com/2014/02/07/what-ismaori-contemporary-dance/ 


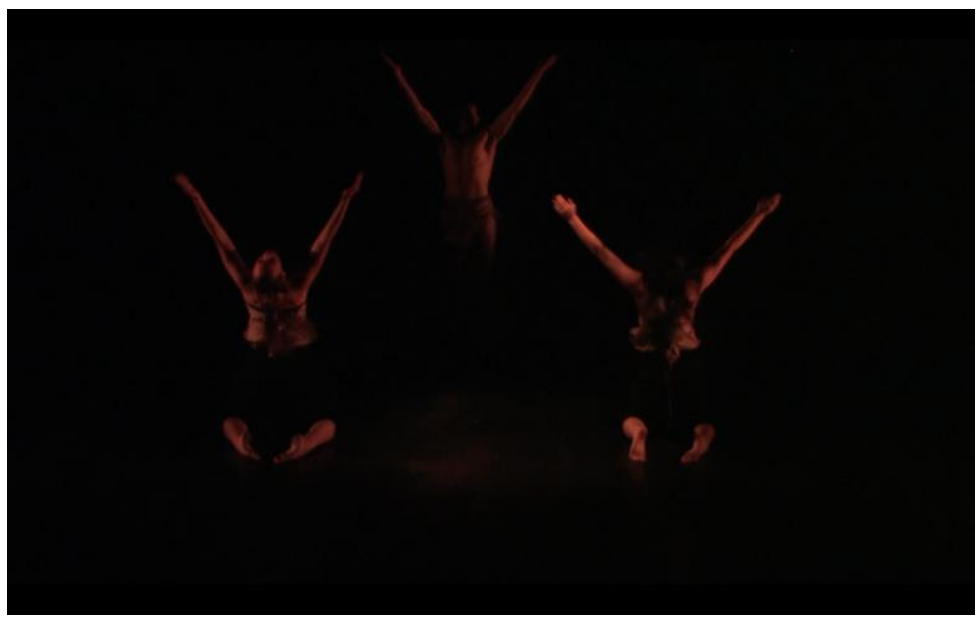

Ringa in Rongo present the viewer with some challenging indigenous terrains for translation. When understanding the meanings that dances can carry, audience members may have insufficient cultural and linguistic knowledge to translate what they are watching and so meaning can pass them by, incommensurably. The traditional source of ringa, according to Shennan (1984), lies in a limited five or six stylised arm gestures found in patere, an early form of action song, in which genealogical connections of the composer and possible geographical landmarks signifying heritage are traced. These early patere gestures, unlike their later counterparts, did not depict nature or literally interpret specific images that occur in the song, as Peirce's icons could do, rather they symbolised defiance and spirited self-assertion. The tradition of haka being one wherein movements are often highly stylised and refer to cultural concepts and ideas that "are not accessible in a way that gestures in the European realistic tradition of mime..." (Shennan, 1984, p. 40). Ringa were later developed as icons, miming recognisable actions such as paddling, hauling up a canoe (waka) or use of a weapon expressing ideas, events and emotions in song's lyrics. However, Shennan maintains that the iconic mimetic gestures were symbolically associated 
with cultural values. For instance, rather than telling a story of a particular waka, a paddling waka ringa action was indicative of group unity. This differentiation of the intentions that the ringa actions carry is profound because an uninformed viewer may misunderstand the meaning being unable to differentiate between the mime and the symbolic significances. Furthermore, in a poetic double functional manner, some ringa only add to the rhythmical punctuation and sound qualities.

Amongst the dominant dynamic, touches of lightness are found in the wiri (hands shaking or trembling: Armstrong, 1964; Shennan, 1984). According to Nathan Matthews (2004) the wiri "is the re-enactment of te haka a Tane- rore from whence haka originates (p. 14). As a key characteristic of haka, therefore, it holds traditional significance carrying both iconic but also culturally deictic symbolic significances from the traditional story of Te Manu-i-te-ra the sun god who had a son with the summer maiden, Hine-raumati. The son, Tanerore, is said to be seen dancing for his mother as a trembling of hot summer air just above the ground when his mother visits the earth. The quivering hands of wiri are called te haka a Taine-rore (the dance of Tane-rore) (Matthews, 2014).

However, in Rongo the wiri also seems to express other overlapping iconic and symbolic cultural significances, making wider references to human relationships with the natural world. Witarina Harris describes the wiri as visible in nature in the leaves on the trees (Shennan, 1984), and Tanemahuta Gray describes it as being present in "The rippling of the water when the wind causes it to stir, or the rustling of the leaves of a tree with a passing wind" (Ashley, 2015). In Rongo the wiri seems to layer both the deictic (indigenously Māori in this case) mythological literary significance with the iconic referential depicting rain, needed to make the crops grow. Again, translating the complex and overlapping dynamism of wiri as a movement sign via a Peircean semiotic alongside Laban analysis, illuminates some nuances of Rongo and brings 
considerable advantages in relation to avoiding incommensurability.

Group formations and relationships in Rongo are of particular interest if viewed from the perspective that this is contemporary haka movement because, unlike a Western contemporary dance choreographic aesthetic, the group formations and relationships in space are relatively restricted. Looking through Western spectacles, retention of the same triangular formation or a line where the male dancer is always at the centre in Rongo could be judged as lacking in 'imagination'. These, however, are the wrong spectacles because what we are watching is a contemporary haka, and as such the rows and symmetrical formations are key to a particular worldview (Armstrong, 1964; Shennan, 1984). Also, gender relationships, as described by Alan Armstrong, feature in which male dancers sometimes move forward through the females are active in Rongo.

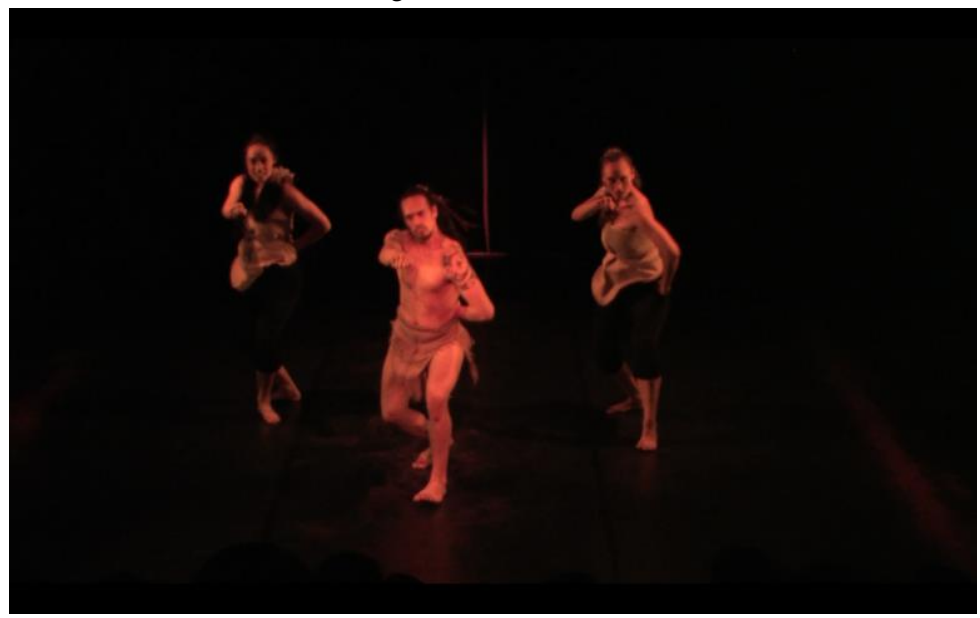

Jennifer Shennan (1984) points out that haka is usually recognised as a group activity, although not entirely. In the trio version of Rongo, the male solo (Karena Koria) is a major feature. Te Ua indicates that: 


\begin{abstract}
Karena's solo was an appeasement /acknowledgement to te Atua Rongo (God of agriculture and peace) and all that he provides with regard to te oranga o te tinana me te wairua (substance of the body through kai maori and also the wairua - spirit. (Te Ua, K., personal communication, February 4, 2015)
\end{abstract}

Also, in terms of group relationships the female performers are usually in a 2 versus 1 relationship through movement to the male soloist, somewhat indicative of Armstrong's description of gender roles. There are however, moments probably unusual to traditional haka such as when the two females, in kneeling position, face each other or the back of the stage. Possibly these are more in the style of relationship variations found in Western contemporary dance terrains, where choreography aspires to find as wide a range of movement as possible.

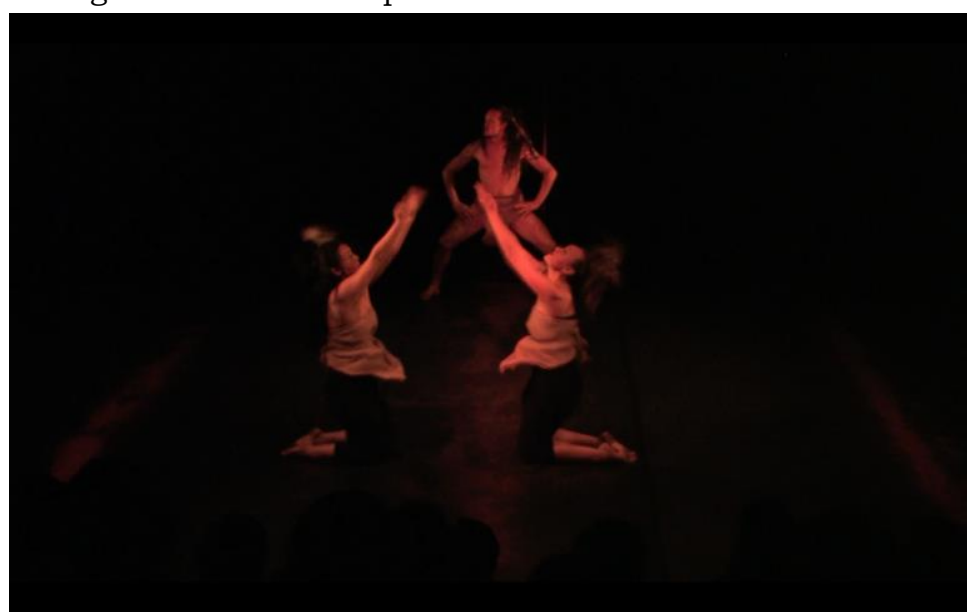

Reflecting on the past, as mentioned above, is a feature of Matariki and by unravelling how the complex, layered, embodied signs function in dynamic relation to each other in Rongo I have illuminated its cultural terrain. 
Mimetic icons oscillate with symbolic, allegoric significances referring to the wairua and relevant myths, on a physical terrain of an explosive dynamic. In reading the three aspects of the dance vocabulary in Rongo I hope to show how a Peircean translation can add substantially to the understanding of this haka dance, going beyond what a Laban movement analysis achieves.

\section{Summary}

In this article I endeavoured to illuminate the significance of certain movement characteristics of Rongo via Laban analysis in symbiosis with Peirce's semiotic classification of signs. By juxtaposing Peircean semiotic translation alongside Laban analysis I am attempting to answer Desmond's (1997) call to provide tools for a broad, close and deep analysis of dance movement that can fluidly shuttle back and forth the between the physical and the contextual with legitimacy.

I have followed a doubly functional translation process in navigating haka's wider literary codes and significances as well as ones specific to Rongo, and I contend that without consideration of both we are left with a guessing game about we are watching. This game may or may not be satisfying depending on the individual viewer or choreographer's point of view. I advocate for Peircean semiotics as a viable, accessible and vibrant additional tool for illuminating codification of identities and socio-cultural norms in indigenous contemporary dance, much as Bannerman did with Western contemporary dance.

As Alan Armstrong (1964) suggests, haka is an art form that mirrors the identity of the entire culture, combining words, posture and passion. Moreover, in combination with Nathan Matthews' (2014) observation that haka demonstrate the importance of movement and are pre-eminent forums for transmitting messages about socio-political ideas and knowledge, I identify a vital indication of the importance of 
trying to find ways that viewers can come to better understand the messages that haka choreographers such as Te Ua and Ngarino Watts may like us to appreciate. Such reasoning also provides grounds for understanding performances of haka, and Rongo in particular, as drawing on the understanding that dance languages can run parallel to, overlap with or synchronise with the spoken word and / or literature, whilst also functioning as culturally specific dynamic and rhythmic terrains. Although, the latter would be best understood if read alongside a parallel reading of the karakia and musical accompaniment.

As a system based on reading language, visual representation and movement, Peircean semiotics, in symbiosis with Laban movement analysis, has been shown to be productive in studying complex kinaesthetic systems of haka as seen in Rongo. The rationale that I have presented in this article, I further argue, reinforces my advocacy for the merits of applying Peirce's three sign classification to illuminate and further inform our understanding of the cultural terrains that dances tread. I also suggested four other advantages that can arise from the application of Peirce's semiotics for those involved with dance and informative for those who may work outside of that art form.

First, applying a combination of Peircean semiotic reading with Laban movement analysis is useful to those who work in dance because it clarifies how dances, when acknowledged as languages, can be awarded equitable status to other arts and epistemologies being also language oriented endeavours. Second, the dynamic interactions of icons and symbols with indexical signs that indicate meaning within the background or context promotes a sense of the importance of reading dance as social texts and brings a possibility for dances to function both kinaesthetically and send important cultural or political messages. Third, the symbiotic process of reading Rongo opens up a depth of cultural understandings that is intentional by choreographers and this, I suggest, is a 
healthy complementary counterpoint to a previous foundation whereby contemporary dance is seemingly arbitrary and mainly driven by the viewer's imaginative interpretation. Finally, the latter may be particularly, although not exclusively, important for First Nation People's heritages and performances as they go about re-establishing, taking ownership of and protecting their lands and presenting their postcolonial worldviews.

In conclusion, I contend that Peircean semiotics provides a tangible strategy that illuminates how haka, and dance more generally, embody substantial and important literate terrains. By fostering understanding of these terrains dance makers and their works can be better understood by those outside our rarified circles. They can also be understood to be working in an art form that is every bit as literate, crucial and politically relevant to the human condition as any other form of knowledge. 


\section{References}

Adshead - Lansdale, J. (Ed.). (1999). Dancing texts, intertextuality in interpretation. London: Dance Books.

Armstrong, A. (1964). Maori games and hakas. Wellington: Reed.

Ashley, L. (2008). Essential guide to dance. (3rd ed.). London: Hodder Educational.

Ashley, L. (2012). Dancing with difference: Culturally diverse dances in education. The Netherlands: Sense Publishers.

Ashley, L. (2013). Culturally different dances in the New Zealand arts curriculum: Understanding about fusion, tradition and making dances in context. In T. Gray, M. Gray, J. Stevenson, L. Ashley, P. Moon \& Peter Cleave (Ed.), Kowhiti Dance: Special Collection (pp. 101-143). New Zealand: Go Press.

Ashley, L. (2014). Encountering challenges in teacher education: Developing culturally pluralist pedagogy when teaching dance from contextual perspectives in New Zealand. Research in Dance Education, 1. doi.org/10.1080/14647893.2014.910186

Ashley, L. (2015, in press). Dancing in Different Tongues: A surplus of meaning in indigenous terrains of contemporary dance. Dance Research Aotearoa. http://www.dra.ac.nz

Bannerman, H.L. (2010). Movement and meaning: an enquiry into the signifying properties of Martha Graham's Diversion of Angels (1984) and Merce Cunningham's Points in Space (1986). Research in Dance Education, 11(1), 19 - 33.

Best, D. (1985). Feeling and reason in the arts. London: George Allen \& Unwin.

Cleave, P. (2014). Memory, body and dance: A review of literature. Te Kaharoa: The e-journal on Indigenous Pacific Issues. 7, 25 - 61. Retrieved May 1, 2014, from

http://www.tekaharoa.com/index.php/tekaharoa/article/view/167/1 $\underline{25}$

Desmond, J. C. (1997). Embodying difference: issues in dance and cultural studies. In J. Desmond (Ed.), Meaning in motion: New cultural studies of dance. (pp. 29 -54). Durham \& London: Duke University Press.

Eagleton, T. (1996). Literary theory: an introductory reader (2nd ed.). London: Blackwell.

Farnell, B. (1994). Ethno-graphics and the moving body. Journal of the Royal Anthropological Institute, 29 (4), 929 - 974. 
Farnell, B. (1999). It goes without saying - but not always. In T. J. Buckland (Ed.), Dance in the field: Theory methods \& issues in dance ethnography (pp. 145 - 160). Hants: Macmillan.

Farnell, B. (2003). Kinesthetic sense and dynamically embodied action. Journal of the Royal Anthropological Institute, 12 (4), 132 144.

Jakobson, R. (1997). Linguistics and poetics. In K. M. Newton (Ed.), Twentieth century literary theory: A reader ( $2^{\text {nd }}$ ed.). (pp. 71 - 77). New York: Palgrave Macmillan.

Jordan, S. \& Thomas, H. (1998). Dance and gender: Formalism and semiotics reconsidered. In A. Carter (Ed.), The Routledge dance studies reader (pp. 241 -249). London: Routledge.

Kaeppler, A.L. (2005). The Tongan Laklaka as socio-political discourse. In I. Campbell \& E. Coxon, (Eds.). Polynesian paradox: Essays in honour of Professor 'I.Futa Helu (pp. 139 - 153). Suva, Fiji: University of the South Pacific.

Kant, M. (2008). Practical imperative: German dance, dancers and Nazi politics. In N. Jackson \& T. Shapiro-Phim (Eds.), Dance, human rights and social justice: dignity in motion (pp. 5-19). Toronto, CA: Scarecrow Press.

Laban, R. (1960). The mastery of movement. (Rev. ed. By L. Ullman). London: Macdonald Evans.

Lepczyk, B. (2009). Celebrating the Laban legacy. Journal of Physical Education, Recreation and Dance, 80(5), 4-5.

Matthews, N. (2004). The physicality of Mäori message transmission Ko te tinana, he waka tuku Korero. Junctures. Journal of Thematic Dialogue, 3, 9 - 18.

Mazer, S. (2011). Performing Maori: Kapa haka on the stage and on the ground. Entertainment Studies 2(1), 41-53.

Mazer, S. (2013, November 7). A case for creative misunderstanding. Paper presented for the Köwhiti Academic Symposium: Atarau - A Beam of Light. Te Papa, Wellington, New Zealand. From the author.

New London Group, The (1996). A pedagogy of multiliteracies: Designing social futures. Harvard Educational Review, 66(1), 60-92.

New Zealand Ministry of Education. (1999). The Arts in the New Zealand Curriculum: A background paper. Retrieved November 22, 2007, from

http://www.minedu.govt.nz/index.cfm?layout_document\&document

Peirce, C.S. (1960). Collected papers of Charles Sanders Peirce. C. Hartshorne, P. Weiss, \& A. Burks (Eds.). Cambridge, MA: Harvard University Press. 
Peirce, C.S. (1982). Writings of Charles S. Peirce: A chronological edition. Volume 1, 1857 -1866. In M.H. Fisch (Ed.), Bloomington, IN: Indiana University Press.

Peirce, C. S. (1982a). Writings of Charles S. Peirce: A chronological edition. Volume 2, 1857-1866. M. H. Fisch (Ed.). Bloomington, IN: Indiana University Press.

Semetsky, I. \& Stables, A. (Eds.).(2014). Pedagogy and Edusemiotics: Theoretical Challenges/Practical Opportunities. Rotterdam: Sense Publishers.

Shennan, J. (1984). The Maori action song. Wellington: New Zealand Council for Educational Research.

Silverstein, M. (2000). Functions. [Electronic version]. Journal of Linguistic Anthropology, 9(1-2), 76 - 79.

Singer, M. (1980). Signs of self: An exploration into semiotic anthropology [Electronic version]. American Anthropological Association, 82(3), 485 - 507.

Smith, H.A. (2005). Peircian theory, psychosemiotics, and education. Educational Philosophy and Theory, 37(2), 191 - 206.

Smith-Autard, J. (2002). The art of dance in education (2nd ed.). London: A. C. Black.

Willams, D. (2003). Signifying bodies, signifying acts: New ways of thinking about human movement. St. Louis Park, MN: Copy Max.

I would like to acknowledge Kowhiti and Dr Peter Cleave for the opportunity to publish this paper. Grateful thanks also to Kura Te Ua for her patience in responding to my questions as I went about improving my understanding of Rongo. Kia kaha! 